\title{
A Importância da Atividade Científica: concepções dos produtores de conhecimento químico de uma universidade pública
}

\section{The Importance of Scientific Activity: the conceptions of producers of chemical knowledge in a public university}

\author{
Ettore Paredes Antunes ${ }^{1}$ \\ Yana Bárbara da Silva Teixeira ${ }^{1}$ \\ Luiz Henrique Ferreira² \\ 1Universidade Federal do Amazonas (UFAM), Departamento de Química, Manaus, AM, Brasil.
Autor correspondente: ettore@ufam.edu.br
${ }^{2}$ Universidade Federal de São Carlos (UFSCar), Departamento de Química, São Carlos, SP, Brasil
}

Resumo: Este artigo discute a complexidade como um caminho para que produtores de conhecimento entendam a atividade científica e sua importância, não simplificando o processo de investigação através do distanciamento do sujeito, mas refletindo criticamente sobre as ambiguidades que acompanham a Ciência. Essa discussão deu-se a partir de um arcabouço teórico da Sociologia da Ciência e através da análise de respostas a entrevistas realizadas com pós-graduandos e docentes de uma universidade pública federal. Os resultados indicaram a percepção das influências externas na atividade científica, porém há pouca reflexão do que elas representam e o que é realmente a atividade científica. A formação de cientistas revela-se utilitarista, acrítica e não reflexiva acerca da complexidade da Ciência.

Palavras-chave: Ensino superior; Produção intelectual; Produção do conhecimento; Formação científica.

Abstract: This research addresses complexity as a way for knowledge producers to understand scientific activity and its importance, not by simplifying the investigative process through the distancing of the subject but, instead, by critically reflecting on the ambiguities that are inherent in Science. This discussion takes place within a theoretical framework of Sociology of Science and with the analysis of responses to an interview provided by postgraduate students and professors of a public, federal university. The results reveal the perception of external influences in scientific activity, but little reflection on what these influences represent on what scientific activity really is. The training of scientists proves to be utilitarian, uncritical and unreflective with regard to the complexity of science. training.

Keywords: Higher education; Intellectual production; Knowledge production; Science

Recebido em: 03/12/2019

Aprovado em: 10/05/2020 


\section{Introdução}

Uma concepção enraizada na cultura científica vigente, que será alvo de críticas e averiguação neste artigo, é a de que a Ciência consiste na investigação do mundo e na formulação de teorias que o representam tal como ele é; sendo essa atividade supostamente neutra, sem nenhuma ligação de valor, pois o cientista se afastaria do objeto para obter os fatos puros e, dali, tiraria suas teorizações e conclusões. No entanto, a observação e a posterior representação de algo implica interações, em relações de perspectiva, como afirmou Lacey (1998, p. 28): "[...] nossa experiência nunca é simplesmente do mundo, mas do mundo em interação conosco. Assim, sabemos que as teorias representam o mundo do modo como ele aparece nas perspectivas das práticas científicas."

Assim, cada pesquisador pode ter uma explicação diferente para um fenômeno por causa dessas interações e experiências, que "[...] são norteadas pelos componentes da sociedade em que os indivíduos estão inseridos, entre eles: crenças, conceitos e convenções sociais" (MEGLHIORATTI; BATISTA, 2018, p. 7). Portanto, as teorias possuem em si algo de não científico, que são os valores, interesses e perspectivas do sujeito que observa, conclui sobre e representa o mundo, de forma que não existe neutralidade na Ciência. Apesar disso, a aceitação de teorias, ou seja, a legitimidade daquele conhecimento, deveria ser imparcial, o que também se verifica como falso, pois a comunidade científica possui seus valores e interesses, não objetivando apenas conhecer a realidade. Isso foi observado por Morin (2005, p. 57): "[...] a ciência não é só isso [atividade de investigação e de pesquisa] e, constantemente, ela é submergida, inibida, embebida, bloqueada e abafada por efeito de manipulações, de prática, de poder, por interesses sociais etc."

Essas manipulações de poder implicam, consequentemente, que a atividade científica, independentemente sobre qual ciência estejamos falando, procederá conforme ditam os valores e interesses que estão em pauta naquele momento. Daí o paradoxo de a sociedade influenciar o trabalho científico e da mesma forma ser influenciada por ele; pois ela utiliza o conhecimento científico produzido de maneira mais conveniente e, mais além, tem demandas de conhecimentos que poderiam ser convenientes. Assim, a sociedade decide sobre o que fazer com os saberes científicos tendo por princípio aquilo que serve aos seus interesses. Dessa forma, "[...] o conhecimento é sempre uma representação daquilo que é possível fazer e, por conseguinte, representação daquilo que poderia ser objeto de uma decisão na sociedade". (FOUREZ, 1995, p. 207).

Portanto, existe um conhecimento que vai de encontro às demandas sociais. Dito isso, cabe aqui fazer distinção entre a ciência pura e a ciência aplicada, especialmente do ponto de vista das ciências da natureza. A ciência dita pura objetiva a aquisição de novos conhecimentos, trabalhando dentro de um laboratório e vista, por isso, como distante da interação social. Já a ciência aplicada é um trabalho com maior relação, pois produz conhecimento com destino social definido. No entanto, distingui-las entre mais e menos influenciadoras ou presentes na comunidade não faz sentido, porque, como dito, a própria atividade científica já parte de uma interação entre o ambiente e o sujeito, e de cientistas com cientistas, para a legitimação de conhecimentos. 
As ciências ligam-se intimamente com o mundo nas suas mais variadas questões, pois dos seus estudos provêm produtos e tecnologias, que interferem na organização social e até mesmo no tipo de sociedade que se institui. Ao se escolher financiar certas pesquisas, transformamos o meio, por exemplo: ao investir em pesquisas referentes ao desenvolvimento de celulares, o meio social-econômico modificou-se, bem como ambientes foram adaptados a essa tecnologia e, consequentemente, temos hoje uma comunidade diferente por causa desse produto. Assim, "[...] a escolha das tecnologias não é, portanto, somente uma escolha de meios neutros, mas uma escolha de sociedade" (FOUREZ, 1995, p. 219).

Para além dessa mútua influência da sociedade na ciência que se desenvolve e viceversa, uma outra relação entre ciência e sociedade é caracterizada pelos poderes que se instituem através da aquisição e valorização do conhecimento, sendo um dos principais o poder hierárquico, pois "[...] qualquer um que seja capaz de realizar um certo número de coisas pode, após um certo tempo, exercer um poder sobre os outros" (FOUREZ, 1995, p. 204). Também cabe destacar a escolha de sociedade; ora, observando o mercado de trabalho podem-se ver as exigências acadêmicas para certos cargos, ou seja, é perceptível a modificação social proveniente do poder adquirido com o conhecimento. A partir disso, as demandas de produção científica serão voltadas para uma sociedade diferente, com novos valores, e serão valorizadas as pesquisas (e as teorias) que sejam condizentes com o paradigma atual do mundo.

Aliás, na prática moderna da ciência, só se considera um conhecimento como interessante na medida em que alcança resultados concretos, geralmente experimentais, no que diz respeito à organização de nosso mundo e à sua representação. (FOUREZ, 1995, p. 203).

Em decorrência dos julgamentos sobre o que é ou não interessante, os produtores de conhecimento, assim como os locais, tendem a aceitar os valores impostos sem reflexão sobre o que é de fato imposto.

Uma razão poderia ser que, considerando a necessidade de condições materiais e sociais para realização de pesquisas, somente as estratégias que oferecessem produtos úteis para os interesses associadas aos valores sociais dominantes ou em ascensão receberiam o suporte necessário para desenvolver-se. (LACEY, 1998, p. 36).

Essas influências externas acerca da disposição de suporte para pesquisa em conjunto aos interesses do próprio pesquisador acabam por trazer uma valorização de certos tipos de atividades científicas. É claro que "[...] os interesses econômicos, capitalistas, o interesse do Estado desempenham seu papel ativo nesse circuito de acordo com suas finalidades, seus programas, suas subvenções" (MORIN, 2005, p. 20). Um exemplo seria o desejo de publicar um artigo que induz pesquisadores a buscarem trabalhar com algo que possa ter aplicação direta na sociedade, a curto prazo e de baixo custo (ou seja, voltam-se para a ciência aplicada), pois isto é para onde os programas e subvenções do Estado olham. As coações tecno-burocráticas levam à produção em massa de conhecimento voltado ao controle da natureza para beneficiar a população ou mesmo a produção industrial, como diz Lacey (1998, p. 43): "[...] a aplicação da ciência moderna, em sua maior parte, serve especialmente às perspectivas de valor e aos projetos morais que têm em alta estima o valor de ampliar a nossa capacidade de controlar a natureza." 
Os valores atuantes, então, tendem a ditar o que deve ou não ser prioridade no trabalho científico. Se os valores já estão inseridos tão profundamente na Ciência e na universidade, não é mais válido fechar os olhos para eles; "[...] a época fecunda da não-pertinência dos julgamentos de valor sobre a atividade científica terminou" (MORIN, 2005, p. 126).

Como já dito, existem os fatores externos e internos referentes à manipulações de poder, porém há mais do que isso. A Ciência e os humanos que a produzem são históricos, sociológicos, culturais, políticos, físicos, biológicos, e carregam também antônimos como a certeza e a incerteza, a ordem e a desordem: "[...] é dessa complexidade que se afastam os cientistas não apenas burocratizados, mas formados segundo os modelos clássicos do pensamento" (MORIN, 2005, p. 9). Esses traços da Ciência são afastados em virtude da simplificação e redução de fenômenos a leis universais, que proporcionaram grandes descobertas, e, no entanto, exigem um sacrifício por isso:

Para que haja uma aproximação e um diálogo entre a inteligência do homem e a realidade ou a natureza do mundo, são precisos sacrifícios enormes: para manter o formalismo ou a quantificação, o conhecimento científico sacrifica as noções de ser, de existência e a integridade dos seres. Deve-se pensar nesse problema, saber o que se sacrifica, o que se deve sacrificar e até onde se deve sacrificar. (MORIN, 2005, p. 58).

É justamente pelo formalismo e pela quantificação, pelo pensamento de representação do mundo tal como ele é, que o produtor de conhecimento não sabe o que sacrifica, não conhece o que produz, não conhece a Ciência com a qual trabalha. Sendo a Ciência aquela que traz o conhecimento, não seria passível de ser conhecida; "[...] o que é elucidativo não precisa ser elucidado" (MORIN, 2005, p. 21). Mas como não precisaria? A complexidade é núcleo da Ciência e, por isso, não existe ciência puramente científica, há sempre em conjunto todos os outros traços que a constituem (cultura, política, entro outros) e, portanto, ela não poderia elucidar o universo em sua totalidade. $E$, mais além, a atividade científica não tem como objetivo nem como função atender às demandas da sociedade, porém possui, sim, poder, possui influência no desenvolvimento da mesma. É preciso enfatizar que essa influência não é apenas boa pelos benefícios ou apenas má pelos malefícios; é na verdade ambos, e isso já constitui um traço complexo da Ciência sobre o qual é necessária a reflexão pelos cientistas.

Sem essa reflexão sobre o que é a Ciência, sobre o trabalho que se faz e sobre as influências no mundo, o conhecimento permanece como está, "[...] produzido para ser armazenado em bancos de dados e manipulado por poderes anônimos" (MORIN, 2005, p. 120), reduzido a leis e não se volta ao diálogo com todos os saberes ambivalentes, ordenados e desordenados ao mesmo tempo, que compõem o universo.

Esse ato de pensar, de refletir e de meditar, como tudo, não é simples. Requer a mudança da mentalidade daqueles que produzem o conhecimento, que ponham sob árdua interrogação o paradigma da simplificação e redução, que ponham, também, sob interrogações os sacrifícios feitos em nome do saber:

A necessidade, para a ciência, de se auto-estudar supõe que os cientistas queiram auto-interrogar-se, o que supõe que eles se ponham em crise, ou seja, que descubram as contradições fundamentais em que desembocam as atividades científicas modernas e, nomeadamente, as injunções contraditórias a que está submetido todo cientista que confronte sua ética do conhecimento com sua ética cívica e humana. (MORIN, 2005, p. 35). 
É preciso tirar as vendas e investigar as responsabilidades e valores da Ciência, investigar o poder de controle sobre o conhecimento produzido. Trata-se de iniciar uma nova mentalidade, "[...] um pensamento capaz de enfrentar a complexidade do real, permitindo ao mesmo tempo à ciência refletir sobre ela mesma" (MORIN, 2005, p. 31).

A transição para esse pensamento deveria partir do seio da produção científica: a universidade. A princípio, a universidade foi criada como uma instituição social, a qual está ligada com as regras e padrões sociais de modo que anda lado a lado com as mudanças do meio e também as proporciona, sendo local de divergência de opiniões que fomenta a descoberta e a criação de novos caminhos e pensamentos. Como enfatizou Chauí (2003, p. 6), "[...] em outras palavras, a instituição se percebe inserida na divisão social e política e busca definir uma universalidade (imaginária ou desejável) que lhe permita responder às contradições, impostas pela divisão". Esse papel social que Ihe cabia permitiria a transição para o pensamento complexo como resposta às necessidades de mudança do meio, assim seria formada nos docentes e discentes a visão de uma Ciência capaz de lidar com suas ambivalências.

No entanto, a universidade passa por uma reforma que a designa não mais como instituição, mas como organização social. Ora, uma organização preocupa-se com a gerência de todas as questões administrativas da melhor forma para alcançar seu objetivo e ser reconhecida como superior às suas concorrentes. Dessa forma, como descrito por Chauí (2003, p. 6), "[...] não Ihe compete discutir ou questionar sua própria existência, sua função, seu lugar no interior da luta de classes [...]", apenas há o planejamento para entregar ao cliente o melhor serviço.

Além disso, para manter-se como organização de qualidade dentro da concorrência, a universidade busca suporte financeiro para manter suas atividades científicas e, para recebê-lo, submete seus docentes, graduandos, pós-graduandos e ela mesma às demandas externas, às exigências de como, em quanto tempo, com quais valores e o que deve ser investigado. Como resultado, temos que a valorização de certos conhecimentos, de certas pesquisas e de certos produtos, o que faz com que a universidade vire as costas para uma ciência investigativa e se transforme em uma espécie de empresa com produção em massa sujeita a órgãos de fomento.

Como mencionado por Chauí (2003, p. 8), "[...] a ciência deixou de ser teoria com aplicação prática e tornou-se um componente do próprio capital". Do capital porque a aquisição de conhecimento produz a já mencionada hierarquia e dá poder para aquele que o detém, seja econômico, seja militar ou outro. Por isso, a todo momento, há exigências por parte dos programas de financiamentos, há busca por mais informações aplicáveis, há busca por mais poder. Segundo Chauí (2003), o fato de a universidade aceitar as demandas sem criticidade e reflexão não indica avanço como instituição formadora, mas o contrário:

[...] isto é, tanto a heteronomia universitária (quando a universidade produz conhecimentos destinados ao aumento de informações para o capital financeiro, submetendo-se às suas necessidades e à sua lógica) como a irrelevância da atividade universitária (quando suas pesquisas são autonomamente definidas ou quando procuram responder ás demandas sociais e políticas de sua sociedade). (CHAUÍ, 2003, p. 9). 
Dessa forma, a universidade vai deixando de lado sua autonomia, seu papel de instituição social e sua função formadora e passa a um estado passivo frente às organizações com capital para investir nela. Deixa de lado sua participação nas mudanças do meio e aceita as demandas dessas organizações. O que, na verdade, é esperado a partir do momento em que não há mais a reflexão, como relatado por Morin (2005, p 161):

Ora, por toda parte onde se esbate ou se dissolve a ideia humanista (tornando-se cada vez mais frágil), por toda parte onde se retira o fermento crítico, a racionalização fechada devora a razão. Os homens deixam de ser concebidos como indivíduos livres ou sujeitos. Devem obedecer à aparente racionalidade (do Estado, da burocracia, da indústria).

É perceptível, então, que a universidade tem paulatinamente deixado de ser o local cheio de contradições, rebuliços e pensamentos revolucionários. Sem o pensamento reflexivo e obedecendo a essa racionalidade de outros órgãos, a universidade passa, como dito, à produção em massa de conhecimento aplicável, diminuindo o período de tempo de descobertas científicas para satisfazer às demandas, cada vez mais exigindo que sejam aprendidas mais técnicas, afastando-se mais da sua função formadora.

Chauí (2003, p. 9) nos leva a pensar em como essas exigências dos órgãos influenciam na qualidade do que está sendo feito em termos de relevância transformadora: "[...] a quantidade de descobertas implicou uma mudança na definição de uma ciência?". O que passou a ser ensinado em uma sala de aula universitária são saberes que formam o indivíduo ou são conhecimentos aplicáveis em empresas para que tenham um currículo exemplar? São saberes que levam ao pensamento divergente ou revolucionário? São conhecimentos que se aproximam da real atividade científica? O que acontece com a própria concepção do que é Ciência dentro da universidade?

Devido a essa aceleração da produção de conhecimento e da exigência de descobertas, a atividade científica e a própria formação humana na universidade perdem seu rumo. Isso passa pela compressão espaço-temporal mencionada por Chauí (2003) em que a noção do espaço e do tempo é abstraída e só existem o aqui e o agora, levando ao sentimento de insegurança por não haver o passado nem o futuro, apenas o momento presente: "[...] ora, sabemos que a insegurança não gera conhecimento e ação inovadora, e sim medo e paralisia, submissão ao instituído, recusa da crítica, conservadorismo e autoritarismo" (CHAUÍ, 2003, p. 10). Como consequência, temos a perda da identidade da universidade como instituição social e a perda do sentido da formação.

As salas de aula tornam-se centros de adestramento das técnicas que as empresas desejam que os indivíduos obtenham, a pesquisa aceita as exigências externas, os professores são contratados para orientarem os universitários desta mesma maneira, e tanto docentes quanto discentes saem do caminho da educação permanente, aprimorando-se não pelo conhecimento novo, mas pela necessidade de adquirir mais técnicas utilizadas nas indústrias. Segundo Chauí (2003, p. 11), "[...] a educação deixa de ser para a vida e torna-se educação durante toda a vida".

Para que a universidade retorne ao caminho formador e revolucionário, divergente e construtor, é necessário, que "[...] o Estado não tome a educação pelo prisma do gasto público e sim como investimento social e político, o que só é possível se a educação for 
considerada um direito e não um privilégio, nem um serviço" (CHAUÍ, 2003, p. 11). Isso passa pela consolidação da autonomia universitária para definir suas normas, da instituição de um debate com a sociedade sobre a universidade e as metas que criaram, em que há críticas e sugestões; passa também pela necessidade da universidade em se comprometer em tornar o ensino superior acessível a todos, partindo da formação de seus discentes e da qualificação dos seus docentes. Passa pela revalorização dos docentes, não mais como transmissores de técnicas, e das pesquisas, da atividade científica universitária.

É um caminho longo para se percorrer, mas pode-se começar a caminhar agora através da qualificação dos docentes para tornar a vista do futuro mais agradável. Isto é, pode-se e deve-se retomar pontos formativos que foram perdidos pela deformação da Ciência pela compressão espaço-temporal e pela produção de conhecimento em massa. O paradigma que obteve domínio sobre a universidade não trouxe o avanço da instituição, "[...] mas é por meio da ação desses ruídos e da ocorrência desses erros que se opera a reorganização da mensagem em outra que, nos casos felizes, pode ser mais rica, e mais complexa do que a mensagem anterior" (MORIN, 2005, p. 301).

A situação da universidade leva à formação de profissionais (futuros professores, cientistas e profissionais) por meio da transmissão de conhecimentos prontos, que não permitem uma reflexão crítica da Ciência e sua atividade, mas limitam-se a uma imagem ingênua e errônea da mesma, afastando-se da realidade da construção dos conhecimentos. Dessa forma, "[...] o melhoramento da educação científica exige como requisito iniludível, modificar a imagem da natureza da ciência que nós professores temos e transmitimos" (CACHAPUZ, 2005, p. 38).

Passa-se uma visão deformada da Ciência também ao tratá-la de forma descontextualizada, colocando-a, como mencionado inicialmente, livre de interações sociais, trabalhando com dados puros e, por causa disso, como neutra; como se o cientista trabalhasse em um lugar isolado (a saber, o laboratório) onde não precisaria tomar decisões que impactassem no meio e que fossem influenciadas por interesses e pelo paradigma vigente. No entanto, "[...] a ciência está no âmago da sociedade e, embora bastante distinta dessa sociedade, é inseparável dela, isso significa que todas as ciências, incluindo as físicas e biológicas, são sociais" (MORIN, 2005, p. 20). Dessa forma, não se pode excluir as relações entre a ciência, a sociedade, o ambiente e a tecnologia. Assim, por exemplo, a tecnologia não pode ser apresentada apenas como aplicação do conhecimento cientifico, pois se ignora a influência da mesma na construção da ciência e o seu próprio desenvolvimento histórico.

Essa imagem é reforçada pela concepção individualista e elitista, quando se deixa de lado o trabalho coletivo e a comunidade científica, em face do gênio isolado que faz descobertas capazes de transformar as concepções de mundo. A Ciência é fruto do esforço e conhecimento de diversas pessoas, como pesquisadores e técnicos, portanto, um trabalho sozinho não derruba todo um sistema teórico. O que leva a esse pensamento é dar voz a conceitos sem todo o seu arcabouço histórico, enfatizando descobertas e eurekas que não condizem com a construção do conhecimento científico. Não existe um conhecimento que foi elaborado ao acaso, antes disso, como Bachelard (2013) nos diz, tudo é resposta a alguma pergunta; e visto que nenhum problema vem pronto, "[...] é necessário formulá-lo de forma precisa, modelando a situação, fazendo determinadas opções de forma a simplificá-lo para o podermos abordar [...]" (CACHAPUZ, 2005, p. 46). Assim, os cientistas formulam perguntas e, dentro do laboratório, escolhem como trabalhar, inventam teorias e modelos, isolam 
do objeto apenas aquilo Ihes parece relevante e controlam as condições de forma que o experimento possa chegar a comprovar sua teoria, e, por fim, o tornam quantificável, concebem um conceito que explica um fenômeno: "[...] dito de outro modo, fazemos recortes na realidade e é por isso que se diz que não existe um fato puro, um fato sem teoria" (MORIN, 2005, p. 43).

A atividade científica descontextualizada, aproblemática, anistórica e ateórica não deixa espaço para o pensamento divergente que leva às transformações, para os debates e discussões que fazem surgir diversas hipóteses, as quais são investigadas e testadas de diferentes formas, buscando a coerência com os conhecimentos já adquiridos e que podem levar à falseabilidade de teorias aceitas na comunidade. Distorce-se o papel de tentativa de explicação, que é própria da teoria, porque esquece-se as incertezas, os erros e a desordem que permeiam o cerne da Ciência, frente a uma organização de conceitos indubitáveis descobertos por gênios ao quais nenhuma mente pode ser comparada, quando na verdade "[...] as teorias resistem durante algum tempo não por serem verdadeiras, mas por serem as mais bem adaptadas ao estado contemporâneo dos conhecimentos" (MORIN, 2005, p. 22).

Chega-se, então, frente a frente com a essência da complexidade da Ciência: seus conceitos nunca estão totalmente acabados e podem ser falseados. A Ciência carrega, além da organização e ordem, aleatoriedade, incerteza, um lado não racional e obscuro que o modelo simplificador não admite, pois esses elementos arruinam o mito da ciência capaz de elucidar completamente o mundo, mas que são alimento de um corpo teórico mais complexo, capazes de dialogar entre o objeto e o observador sem reduzi-los um ao outro.

Cabe ao docente buscar e trazer aos alunos essa mudança de concepção da Ciência "[...] que deve deixar de ser noção linear, simples, segura e irreversível para tornar-se complexa e problemática" (MORIN, 2005, p. 97). Isto exige uma ação reflexiva e crítica sobre as suas concepções do que é Ciência, do que é atividade científica, como se situa o trabalho científico no mundo, sobre as interações e as influências que este sofre, sobre o papel da Ciência. Se se pretende conhecer o universo, é preciso "[...] não só arrancar dele o que pode ser determinado claramente, com precisão e exatidão, como as leis da natureza, mas, também, entrar no jogo do claro-escuro que é o da complexidade." (MORIN, 2005, p. 191).

De modo geral, as pesquisas na área de Ensino de Ciências buscam contextualizar a Ciência, ultrapassando visões ina dequadas apontadas por Cachapuz (2005) e desenvolvendo o pensamento crítico. Como o trabalho de Conrado e Conrado (2016), o qual busca superar uma visão relacionada ao cientificismo, ou seja, a supervalorização da Ciência, ao abordar o uso de agrotóxicos para identificar interesses que movimentam o setor agrícola e a Ciência feita para esse setor. Já Salvi e Antunes (2009) analisam as concepções de estudantes do Ensino Médio sobre a natureza da Ciência, se são apropriadas ou não; sendo apropriado aquele pensamento que reconhece os valores que influenciam a Ciência. Em maioria, os artigos com base na complexidade de Morin possuem o mesmo objetivo e trazem esse pensamento crítico e complexo a partir da Abordagem CTSA. Um exemplo disso é o trabalho de Veloz, Alves e Brito (2018) que discute a relação da abordagem CTSA e o pensamento complexo, presente principalmente no discurso da integração das partes para entender o todo, no caso, o mundo e suas interações, fomentando o desenvolvimento da criticidade e da compreensão solidária e ética, necessárias frente aos temas CTSA. Além disso, Jacobi (2005) aborda a educação ambiental e sua relação com a transdisciplinaridade e o pensamento complexo, visto que é necessário entender todas a partes de uma situação socioambiental e 
integrá-las para entender o todo e pensar criticamente como reconstruí-lo de uma maneira não agressiva ao futuro do meio ambiente. Já Samagaia e Peduzzi (2004) buscaram reproduzir um tipo de Projeto Manhattan, o desenvolvimento de uma bomba nuclear, trazendo para discussão todos os fatores que envolviam a construção desse armamento.

No entanto, "[...] ainda são relativamente poucos os estudos que estão sistematicamente fundamentados em autores ou tradições originadas da Sociologia da Ciência ou da Sociologia do Conhecimento Científico [...]" (MEGLHIORATTI; BATISTA, 2018, p. 2), especialmente em se tratando da formação daqueles que produzem o conhecimento, a saber: os pós-graduandos. Assim, esta pesquisa busca unir-se a esses poucos trabalhos ao investigar a atividade científica e a formação de cientistas em uma perspectiva do pensamento complexo de Morin. Então, o presente artigo teve a seguinte questão norteadora: o que pensam pós-graduandos e professores universitários de um curso de Química de uma universidade pública sobre a importância da atividade científica, em especial nas relações entre as ciências básicas e aplicadas e no papel dos órgãos de fomento, buscando compreender se há a reflexão sobre a interação do campo científico com outros, e as influências que podem estar obscuras.

\section{Materiais e Métodos}

A presente pesquisa caracteriza-se com um estudo qualitativo do tipo exploratório e buscou identificar o que pensam alunos de pós-graduação e professores da Química, membros de uma universidade pública federal situada no Sudeste. Para tanto, foi utilizado um roteiro de entrevista semi-estruturado e analisadas as respostas dadas para duas perguntas: na Química, são mais valorizadas as pesquisas de base ou as pesquisas tecnológicas? e os órgãos de fomento devem definir prioridades nas pesquisas? Participaram da coleta de dados 35 alunos de um programa de pós-graduação em Química e 16 docentes, os quais foram sorteados a partir das diferentes áreas da Química, excluindo-se a área de Ensino de Química (FísicoQuímica, Analítica, Inorgânica e Orgânica). Para cada entrevistado foi dado um código: os docentes foram denominados P1, P2, P3, etc. e os pós-graduandos receberam um código composto por: a letra M (mestrado), D (doutorado) ou P (pós-doc) inicial que representa o nível do curso que está realizando, e um número; em seguida a letra P de professor, e o número do professor que o orienta.

Para analisar as respostas, utilizamos a Análise Textual Discursiva, como discutido por Moraes e Galiazzi (2011), uma técnica na qual busca-se nas falas (textos) unidades de significado que serão classificadas em categorias de análise. Essas categorias são conjuntos de descritores que indicam tendências numéricas frente ao conjunto de respostas dos pesquisados, pois em cada categoria serão alocadas quantidades de unidades de significado, que representam as ideias gerais das falas. Por fim, realiza-se a interpretação dos resultados, momento de se refletir, comparar, cruzar e projetar o significado da quantidade de unidades por categorias.

\section{Resultados e Discussões}

Para a pergunta na química, são mais valorizadas as pesquisas de base ou as pesquisas tecnológicas?, respondida por professores e pós-graduandos, foram elaboradas quatro 
categorias: (1) Base, na qual foram alocadas as unidades que remetem à valorização da pesquisa de base; (2) Tecnológica, categoria que contém as unidades de significado que representam a valorização da pesquisa tecnológica; (3) Ambas, na qual foi reconhecida a valorização de ambas as pesquisas; e (4) Não sei, na qual foram alocadas respostas confusas ou que o sujeito não havia pensado sobre o assunto. A categoria (2) possui três subcategorias de acordo com o motivo apresentado para a valorização das pesquisas tecnológicas: (2.1) Curtas, o entrevistado não esclarece o motivo; (2.2) Resultados rápidos, unidades que representam o pensamento de que os resultados que são obtido mais rápidos e também podem ser rapidamente aplicados são a razão para a valorização; e (2.3) Órgãos de fomento, unidades representativas da valorização das pesquisas tecnológicas primeiramente pelos órgãos de fomento.

Para a pergunta os órgãos de fomento devem definir prioridades nas pesquisas? foram elaboradas três categorias: (1) Sim, (2) Demandas sociais, permitindo outros temas e (3) Não. Essa pergunta foi respondida apenas por professores.

Quando observamos, para a primeira pergunta, as falas daqueles que consideram a pesquisa de Base (1) como mais valorizada, é perceptível que ela é vista majoritariamente como algo desenvolvido dentro da universidade e para a formação dos alunos (grifos nossos).

D1P5: Na pesquisa de base, principalmente aqui na Universidade como universidade, pesquisa de base sem dúvida.

P1P13: [...] a gente pensa em base, porque a gente pensa em Universidades, você está pensando mais nessa parte de formação.

P13: Tecnológicas acho que não muito, nós somos mais voltados para a parte científica. [...] Meu objetivo maior aqui é formação de recursos humanos. Além das publicações, é claro, mas o objetivo maior é o aluno. Tanto a nível de graduação e principalmente de pós-graduação.

Pode-se pensar dessa forma porque, em seu cerne, a pesquisa de base "[...] não se preocupa muito com as possíveis aplicações em um contexto societário, concentrando-se na aquisição de novos conhecimentos." (FOUREZ, 1995, p. 195). Como percebido na fala do professor P13: "o objetivo maior é o aluno"; entendida como a formação do graduando, daí a importância de adquirir novos conceitos. Porém, observando a mesma fala, há uma remissão a algo comum no meio científico: a pressão por publicação. Cabe pensar, portanto, que se a formação indicada pelos docentes tem por fim o desenvolvimento da criticidade e reflexividade, sendo verdadeiramente formativa, ou se é favorecida a "[...] transmissão entre pesquisadores e treino para novos pesquisadores. Transmissão e adestramento" (CHAUÍ, 2013, p. 7).

Durante a análise das falas que consideram as pesquisas Tecnológicas (2) como as mais valorizadas, houve quatro respostas curtas (2.1) de pós-graduandos e uma de docente, que não são passíveis de análise por falta de conteúdo, por não se saber o motivo para acatála como a pesquisa de preferência, como podemos observar nos exemplos típicos dessas respostas abaixo (grifos nossos): P1 P5: "Olha, o ideal seria que ambas fossem valorizadas, mas eu acredito que as tecnológicas hoje em dia são mais valorizadas do que as básicas". D2P7:

\section{"Tecnológicas".}

Já as demais, ao serem examinadas, nos permitiram observar dois grandes motivos para a notoriedade de pesquisas tecnológicas, ambos relacionados a demandas externas. O primeiro motivo é percebido pela pressão, exterior ao meio científico, para 
desenvolvimento de produtos e pesquisas que fomentem o progresso econômico, social, político e tecnológico da sociedade. Em outras palavras, há busca por resultados mais rápidos (2.2) que atendam as demandas sociais. Como podemos ver nos exemplos de fala (grifo nosso) a seguir, especialmente na resposta do pós-graduando P1P12, a aplicação foi termo muito significativo e representativo dessa subcategoria:

M1P10: E aí tem pesquisa de base de conhecimento muito complexo, aí muita gente fala 'ah para que que vai usar?'

P1P12: [...] você tem uma aplicabilidade maior, a visão da indústria [...]

M1P13: [...] o pessoal está procurando muitas inovações [...]

Desenvolve-se uma ciência que não é voltada para a investigação em si, mas para a utilidade; "[...] a ciência utilitarista é a do desenvolvimentismo, do industrialismo, sobretudo, é a do Mercado" (BOMFIM, 2009, p. 5). Essa relação com as indústrias, com vendas e com a utilidade de algo leva os pesquisadores a aceitarem os termos da compressão espaçotemporal, na qual a produção de conhecimento guia-se pelo capitalismo e pelas ideias e objetivos de uma empresa, ou seja, "[...] em termos de custo-benefício, pautada pela ideia de produtividade, que avalia em quanto tempo, com que custo e quando foi produzido" (CHAUÍ, 2013 , p. 8). Toda essa pressa decorre da possibilidade de que tais pesquisas aumentem nossa capacidade de controlar a natureza, o que condiz com o paradigma mecanicista vigente.

Dessa forma, muitos são os que buscarão aproveitar-se dos poderes proporcionados pelos saberes científicos, o segundo motivo: financiamentos provenientes dos órgãos de fomento (2.3). O termo verbas foi uma unidade de significado representativa dessa subcategoria; pela palavra, já é possível fazer-se presente a ideia de que a ciência produzida se tornou tão indissociável do capital que proporciona pela sua aplicação tecnológica "[...] a ponto dessa aplicação acabar determinando o conteúdo da própria investigação" (CHAUÍ, 2013, p. 9).

D1P4: Creio que é mais por uma questão... de conseguir verbas para projetos. Então, se você não botar um embasamento tecnológico, fica mais difícil.

P3: E você vê que os colegas, os pesquisadores né, que fazem uma pesquisa aplicada eles têm mais recursos, mais fácil, do que aqueles que fazem pesquisa simplesmente básica.

P4 : [...] se você for só vender uma ideia pra qualquer agência de fomento que tenha basicamente só ciência básica é difícil de você conseguir financiamento. [grifos nossos]

Observa-se, então, que a ciência tem novo motivo de existência que não a investigação e compreensão do mundo, "[...] a ciência precisa ser útil, e útil é aquela capaz de atrair investimentos. Pressupõe-se assim, de forma equivocada, que a relevância de uma pesquisa se dá por sua capacidade de atrair recursos" (BOMFIM, 2009, p. 5). Fica clara, pelas falas do D1P4 e do P3, essa preocupação em relacionar os projetos de pesquisas desenvolvidos nos programas de pós-graduação com a captação de recurso financeiro dos órgãos de fomento. A fala de P4 afirma categoricamente: "só ciência básica é difícil de você conseguir financiamento". Esse certamente é o ponto central do presente trabalho: a estreita relação entre o conhecimento científico, liberdade de pensamento, financiamento e importância. 
Buscando aproveitar os poderes e resultados obtidos através de tais pesquisas, "[...] somente as estratégias que oferecessem produtos úteis para os interesses associadas aos valores sociais dominantes ou em ascensão receberiam o suporte necessário para desenvolver-se" (LACEY, 1998, p. 36). Portanto, passa-se a valorizar a ciência proveniente da torre de marfim, sem lembrar que a notoriedade dela se dá, justamente, por suas interações, por seus produtos úteis, pelos interesses de terceiros, por suas aplicações na sociedade, nas indústrias e no jogo de poder.

As representações que produzimos estão sujeitas aos interesses, valores e interações, os quais primeiramente deram origem ao problema estudado, e esse problema só foi possível pelas influências da ciência no tipo de sociedade que temos. A maioria dos pesquisadores - conforme este artigo busca evidenciar - não reflete sobre os valores que estão envolvidos com o tipo de ciência que se faz e a influência que ela tem, antes pensam apenas pelo fator publicação e verbas, tomando o que produzem como neutro que "[...] não serve de modo especial aos interesses de nenhuma perspectiva de valor particular" (FOUREZ, 1995, p. 20), mas pode ser aplicada por qualquer uma delas. Um exemplo disso está presente na fala do P16 citada anteriormente, na qual não há uma reflexão sobre o que investimento de empresas significa em questões de interesses e valores que influenciam a atividade científica. O progresso proporcionado pelas aplicações, independente da perspectiva, deve ser antes objeto de crítica e reflexão do cientista, "[...] porque a ciência crítica, motivada pela reflexividade, tem por interesse a emancipação dos homens, enquanto os outros interesses conduzem à dominação e à sujeição" (MORIN, 2005, p. 47).

Examinando as falas que enfatizam a importância de Ambas (3), vem à tona outra função para a ciência de base, além da formativa; ela possibilita o desenvolvimento de conceitos importantes por uma razão bem específica. É perceptível nas falas de muitos entrevistados que a tecnologia é uma consequência da ciência de base, de forma que a última é feita para ser aplicada, ou ser o fundamento da primeira, justificativa para se produzir pesquisas de base em primeiro lugar. As falas (grifo nosso) a seguir exemplificam essa ideia:

P6: Sempre são complementares, não existe uma pesquisa aplicada que não tenha
um fundamento teórico e vice-versa, o contrário também é verdadeiro.
P4: Eu acho que deveria ser os dois porque muitas vezes uma pesquisa básica vai levar
a uma aplicação bastante interessante no futuro.
P1P1: [...] sem a química básica você não consegue uma aplicação tecnológica e sem
uma aplicação tecnológica você não consegue justificar porque está usando a
química básica.

Essa ideia de consequência nasce da visão sobre a Ciência como algo que será aplicado ou será desenvolvido para tornar-se um produto que a sociedade decide se serve a uma demanda ou a um interesse próprio dela e, portanto, se tem valor, como foi mencionado inicialmente: "[...] o conhecimento é sempre uma representação daquilo que é possível fazer e, por conseguinte, representação daquilo que poderia ser objeto de uma decisão na sociedade" (FOUREZ, 1995, p. 207).

Outra tendência observada nas falas dos docentes é "a dependência do lugar", revelando que, apesar de as duas serem valorizadas, são desenvolvidas em espaços separados e específicos. A fala a seguir é bastante representativa desta tendência: P16 (grifo nosso): "Existem vocação pras duas coisas, a gente percebe que alguns departamentos têm vocação mais para o básico, outros mais para o aplicado." 
Isso indica a diferenciação entre as duas ciências pela dificuldade de reconhecer o conjunto, o todo, que as bases e tecnológicas são partes do mesmo sistema chamado ciência, voltando-se para termos como área de pesquisa ou vocação. Ou seja, compreendese o sistema apenas por uma de suas partes, contudo o "[...] 'todo' não [é] redutível às partes, porque dispõe de qualidades emergentes e de coações próprias [...]" (MORIN, 2005, p. 198).

As respostas que foram alocadas na categoria Não sei (4) denotavam que o entrevistado não havia pensado sobre o assunto ou sua fala foi confusa e não exibiu sentido ou significado que pudesse ser analisado. Apontam a falta de reflexividade e crítica, como podemos ver nos exemplos abaixo (grifos nossos), em especial a do P1P1, que representa o conjunto de unidades dessa categoria: D1P8: "Na área da química? Na química analítica... na química em geral, né? Eu acho que é a mais a química de base que é mais valorizada, sim". P1P1: "Então, eu não sei..."

Toda a valorização percebida nos leva aos órgãos de fomento e às pesquisas que são valorizadas pelos editais de fomento, as quais visam também à aplicação dos saberes no desenvolvimento do país, atendendo demandas da nação, como mencionado por P7, P6, P4 e especialmente P12: "todos os órgãos já, realmente, estão atuando, que é a zika. Se você pegar a CNPq, FAPESP, estão todos eles"; o que nos leva à segunda pergunta sobre as prioridades definidas pelos órgãos. Entre os professores, há aqueles que reconhecem a necessidade de que os órgãos de fomento definam sim as prioridades (1), tendência observada em 37,5\% dos entrevistados e categorizados. Abaixo, elencamos exemplos de falas (grifo nosso) que evidenciam a defesa pela existência de prioridades:

P8: Eu acho que sim, acho que tem que direcionar...

P10: Então quem tem que ditar o que fazer são as necessidades do país...

P13: Agora, pode ter verbas direcionadas para onde a gente acha que deve encaminhar o país, ou para o que a gente precisa.

Essas demandas sociais também são lembradas pelos $50 \%$ dos professores que acreditam que os órgãos de fomento devem incentivar pesquisas que se voltem para seus objetivos de desenvolvimento nacional, mas também permitir que outros temas tenham espaço para serem pesquisados, ou seja, aqueles incluídos na categoria (2).

P1: Então eu acho que esse modelo... e como a sociedade tem as suas necessidades também há a necessidade de direcionar então mas eu acho importante não ter só direcionado seria muito ruim, que haja a possibilidade das pessoas formularem questões que não são as que nesse momento são demandadas pela sociedade... P6: Aí teremos outra... sim e não. Primeiro tem que dar liberdade, acho que isso é uma grande característica. Segundo, eles podem dirigir em algumas frentes por necessidade particulares...

P7: Eu acho que não. Não de uma forma geral, ou seja, toda a pesquisa não, cada pesquisa não. Mas eu acho importante que se lance editais, e aí esses editais seriam direcionados...

[grifos nossos]

Há uma ideia da necessidade de "[...] uma ciência integral, permanentemente atenta ao seu papel social, mas que engendre intelectuais capazes de elaborar grandes sínteses e de propor mudanças de rota" (BOMFIM, 2009, p. 6). É perceptível uma visão de dívida 
com a sociedade, pelas questões de dinheiro público, na qual a orientação de "[...] projetos propostos por setores do Estado que fizeram levantamentos locais e regionais determinadas e que serão subvencionadas pelas agências" (CHAUÍ, 2013, p. 15). Há, de fato, uma relação entre a pesquisa universitária e a necessidade social, no entanto, não deve ser partilhada a imagem que se revela na seguinte fala (grifos nossos): P10: "Quer dizer, você separa um dinheiro para isso, tá certo?, mas os grandes temas têm que ser incentivados porque esse é o papel do cientista, usar o conhecimento dele para gerar coisas úteis para a sociedade."

Ou seja, de uma ciência salvadora, benéfica e capaz de resolver os problemas. Ainda que haja grande influência do que é produzido no meio e no desenvolvimento global, "[...] é preciso saber que a ciência e a razão não têm a missão providencial de salvar a humanidade" (MORIN, 2005, p. 125). Assim, considerando-se que a ciência é uma atividade de investigação, deve ser completamente possível e plausível que pesquisadores tenham liberdade de olhar para temas que lhe são interessantes, desde que seja às claras, porquanto no caminho de retornar ao seu papel como instituição social, "[...] a universidade deve publicamente prestar contas de suas atividades de investigação à sociedade e ao Estado" (CHAUÍ, 2013, p. 15).

No entanto, pela preferência para a ciência aplicada, os temas de pesquisa muitas vezes são escolhidos justamente para ser algo que atrairá financiamentos, tendo interesses que servem ao capital. No entanto, há as falas que não acham que os órgãos devem definir prioridades (3), correspondentes a $12 \%$ dos professores, pois as pesquisas precisam ser valorizadas por outros pontos, como a qualidade. Vejamos a seguinte fala (grifo nosso): P9: "Não. Deve ter mérito. Que critério é dado para fomentar uma pesquisa, ou com bolsa ou com financiamento? O trabalho tem que ter mérito, mas não deve ter prioridade."

É perceptível que a transformação da universidade em uma organização, torna seus membros produtores que não refletem sobre sua prática, pois "[...] numa organização não há tempo para reflexão, a crítica, o exame de conhecimentos instituídos, sua mudança ou sua superação" (CHAUÍ, 2013, p. 7). Assim, pesquisadores estão embebidos em uma visão ingênua e neutra da ciência, afastando-se do seu cerne complexo, e é observado que os professores têm maior consciência dos jogos de poder ao qual são submetidos do que os pós-graduandos. Porém, sendo todos produtores de conhecimento, é preciso saber o que está sendo sacrificado ao se entrar nesse jogo da complexidade das interações que regem o fazer ciência atual, ou seja, daquilo que está implícito na atividade científica: D2P1 (grifo nosso): "[...] eu penso que isso é um problema... ele torna um problema... como eu posso me expressar? Político, social, econômico, ele está envolvido. Entendeu? Porque fazer ciência não é tão simples como se imagina. Entendeu?"

É preciso que o docente, reconhecendo não se aprofundar nas interações que ocorrem entre a ciência e o meio, para que de fato ocorra a atividade científica, supere as visões deformadas que acabam permeando a mente dos universitários, principalmente a visão neutra, descontextualizada e ingênua da ciência, sendo essas visões "[...] o resultado da ausência, quase absoluta, de reflexão epistemológica e de aceitação acrítica de um ensino por simples transmissão de conhecimentos [...]" (CACHAPUZ, 2005, p. 63).

Faz-se importante ser reconhecido que "[...] nem o Estado, nem a indústria, nem o capital são guiados pelo espirito científico: utilizam os poderes que a investigação científica Ihes dá" (MORIN, 2005, p. 20). Aqueles que proporcionam tal poder, os cientistas, são aqueles que devem colocar sua prática sob reflexão crítica, e também é necessário que a universidade seja uma instituição social, capaz de ser o local para essa tomada de consciência, para que faça surgir uma ciência capaz de se pôr como objeto de estudo e que tenha meios para: 
[...] distinguir e fazer comunicar em vez de isolar e de separar, a reconhecer os traços singulares, originais, históricos do fenômeno em vez de ligá-los pura e simplesmente a determinações ou leis gerais, a conceber a unidade/multiplicidade de toda entidade em vez de a heterogeneizar em categorias separadas ou de a homogeneizar em indistinta totalidade. (MORIN, 2005, p. 334).

Assim, a Ciência pode ser percebida não pelas suas partes básicas ou tecnológicas, mas como um todo multidimensional e complexo, indissociável das interações do investigador com o meio em que está inserido, e tratada de forma crítica e reflexiva.

\section{Conclusões}

O presente artigo teve como principal horizonte colocar em pauta uma discussão por vezes negligenciada nas instituições que produzem efetivamente os conhecimentos científico e tecnológico: as universidades públicas. Analisar o que pensam os atores desse processo (pesquisadores em formação ou formadores) pode evidenciar alguns sintomas de um pensamento e uma formação deformadas sobre a atividade científica.

Como tentamos evidenciar, as respostas dos pós-graduandos e docentes remetem a uma ideia problemática, sobre a qual refletimos e criticamos no presente artigo: a pesquisa que alcança publicações e financiamentos, e em geral reconhecimento, é aquela que tem uma aplicação voltada para o desenvolvimento da sociedade, ou seja, que é útil. Mesmo quando os produtores de conhecimento afirmam a importância da pesquisa de base, buscando novos conhecimentos, enfatiza-se que estes devem levar a algum resultado proveitoso no que diz respeito à aplicação e à tecnologia. Dessa forma, tais concepções são ingênuas e contaminadas com um senso comum de utilidade do conhecimento e de consequência, ou seja, o desenvolvimento da ciência de base consequentemente leva à um avanço tecnológico. Ficam claras as influências de perspectivas de valor no que é investigado e no que é valorizado e a aceitação disso por parte dos pesquisadores e da universidade, que já incorporaram esses princípios de custo-benefício no seu pensamento sobre o que é fazer Ciência.

O aspecto da formação dos futuros cientistas na universidade, como denunciado por Chauí, praticamente ficou oculto nas falas, apenas P1P13 e P13 mencionaram a formação. De modo geral, não há a preocupação com a compreensão da atividade científica e com a própria Ciência por aqueles que produzem conhecimento; percebe-se a transmissão para os alunos da própria falta de reflexão dos docentes sobre a perda do sentido de investigação para a necessidade de utilidade, e também a falta de criticidade sobre o que representam todas as influências na pesquisa, por que elas existem, o que objetivam. Os cientistas são ainda formados por um pensamento clássico da Ciência, que não reconhece a complexidade mencionada por Morin (2005).

Por fim, buscamos trazer reflexões de maneira mais ampla do processo de pesquisa científica e a formação de futuros cientistas, incorporando elementos do campo que podemos denominar de Sociologia da Ciência, na tentativa de diagnóstico das universidades e programas de pós-graduação. 


\section{Referências}

BACHELARD, G. A formação do espírito científico: contribuição para a psicanálise do conhecimento. São Paulo: Contraponto, 2013.

BOMFIM, A. M. Fazer ciência social no interior das hard sciences: um ensaio sobre a prática docente em cursos de licenciatura em física, química e matemática. Ciências \& Ideias, Nilópolis, v. 1, n. 1, p. 56-68, 2009. Disponível em: https://revistascientificas.ifrj.edu.br/revista/index.php/reci/article/ view/29. Acesso em: 2 set. 2020.

CACHAPUZ, A.; GIL-PÉREZ, D.; CARVALHO, A. M. P.; PRAIA, J.; VILCHES, A. Superação das visões deformadas da ciência e da tecnologia: Um requisito essencial para a renovação da educação científica. In: CACHAPUZ, A. A necessária renovação do ensino das ciências. 2. ed. São Paulo: Cortez, 2005. p. 37-70.

CHAUÍ, M. A universidade pública sob uma nova perspectiva. Revista Brasileira de Educação, Rio de Janeiro, n. 24, p. 5-15, 2003. DOI: https://doi.org/10.1590/S1413-24782003000300002.

CONRADO, M. S.; CONRADO, I. S. Análise crítica do discurso sobre imagens da ciência e da tecnologia em argumentos de estudantes de biologia. Revista Pesquisa Qualitativa, São Paulo, v. 4, n. 5, p. 218-231, 2016. Disponível em: https://editora.sepq.org.br/rpq/article/view/40. Acesso em: 10 set. 2020.

FOUREZ, G. Construção das ciências: introdução à filosofia e à ética das ciências. São Paulo: Editora UNESP, 1995.

JACOBI, P. R. Educação ambiental: o desafio da construção de um pensamento crítico, complexo e reflexivo. Educação e Pesquisa, São Paulo, v. 31, n. 2, p. 233-250, 2005. DOI: https://doi.org/10.1590/ S1517-97022005000200007.

LACEY, H. Ciências e valores. In: LACEY, H. Valores e atividade científica. São Paulo: Discurso Editorial: Fapesp, 1998. p. 19-45.

MEGLHIORATTI, F. A.; BATISTA, I. D. L. Perspectivas da sociologia do conhecimento científico e o ensino de ciências: um estudo em revistas da área de ensino. Investigações em Ensino de Ciências, Porto Alegre, v. 23, n. 1, p. 1-31, 2018. Disponível em: https://www.if.ufrgs.br/cref/ojs/index.php/ ienci/article/view/726. Acesso em: 10 set. 2020.

MORAES, R.; GALIAZZI, M. C. Análise textual discursiva. 2. ed. Ijuí: Editora Unijuí, 2011.

MORIN, E. Ciência com consciência. 8. ed. Rio de Janeiro: Bertrand, 2005.

SALVI, R. F.; ANTUNES, F. A Ciência e seus valores: uma investigação sobre concepções de alunos do ensino médio. In: ENCONTRO NACIONAL DE PESQUISA EM EDUCAÇÃO EM CIÊNCIAS, 7., 2009. Anais [...]. Florianópolis: Universidade Federal de Santa Catarina, 2009. p. 1-11.

SAMAGAIA, R.; PEDUZZI, L. O. Q. Uma experiência com o projeto Manhattan no ensino fundamental. Ciência \& Educação, Bauru, v. 10, n. 2, p. 259-276, 2004. DOI:_https://doi.org/10.1590/S151673132004000200008 .

VELOZ, V. A.; ALVES, A. S.; BRITO, M. A. A. Conhecimento complexo e a abordagem CTS: contribuições para o ensino de química. In: CONGRESSO NACIONAL DE EDUCAÇÃO, 5., 2018. Anais... [...]. Olinda: Centro de Convenções de Pernambuco, 2018. Disponível em: https://editorarealize.com.br/artigo/ visualizar/46767. Acesso em: 12 nov. 2019. 